\title{
INVESTIGATION OF PHOSPHORUS RELEASE DURING ANNEALING OF Au CONTACTS TO InP
}

\author{
A. Piotrowska, E. Kamińska, \\ Institute of Electron Technology, Al. Lotników 32/46, 02-668 Warszawa, Poland \\ S. KWIATKowski and A. Turos \\ Institute of Nuclear Studies, Hoża 69, 00-682 Warszawa, Poland
}

\begin{abstract}
The analysis of phosphorus release from $\mathrm{Au} / \mathrm{InP}$ contacts heat treated at temperature from the range $360-480^{\circ} \mathrm{C}$ showed that $\mathrm{P}$ evaporation accompanies any stage of contact reaction. The use of encapsulating layer during contact annealing suppresses the loss of phosphorus and changes the kinetics of thermally activated interfacial reaction.
\end{abstract}

PACS numbers: $73.40 . \mathrm{Ns}$

Formation of the $\mathrm{Au} / \mathrm{InP}$ interface is of considerable scientific interest from both, fundamental and practical, viewpoints. Gold has been shown to disrupt readily InP surface $[1,2]$. Contact reaction is highly persistent: indiffusion of In into $\mathrm{Au}$ metallization has been detected in contacts aged in room temperature [3], a series of thermally activated reactions between gold metallization and InP substrate has been observed at temperatures from the range $320-480^{\circ} \mathrm{C}[3-8]$. These follows:

$$
\begin{aligned}
& \mathrm{Au}+\mathrm{InP} \rightarrow \alpha-A u I n+\mathrm{P}_{4}, \\
& \alpha-A u I n+\operatorname{InP} \rightarrow \mathrm{Au}_{3} \mathrm{In}+\mathrm{Au}_{2} \mathrm{P}_{3}+\mathrm{P}_{4}, \\
& \mathrm{Au}_{3} \mathrm{In}+\mathrm{Au}_{2} \mathrm{P}_{3}+\mathrm{InP} \rightarrow \mathrm{Au}_{9} \mathrm{In}_{4}+\mathrm{Au}_{2} \mathrm{P}_{3}+\mathrm{P}_{4}, \\
& \mathrm{Au}_{9} \mathrm{In}_{4}+\mathrm{Au}_{2} \mathrm{P}_{3}+\mathrm{InP} \rightarrow \mathrm{AuIn}_{2}+\mathrm{P}_{4} .
\end{aligned}
$$

While previous investigations of thermally activated processes associated with $\mathrm{Au} / \mathrm{InP}$ interaction concentrated on the analysis of contact microstructure, little attention has been paid to the sublimation of phosphorus under these conditions. This was partly because phosphorus seemed to be bounded by $\mathrm{Au}$ forming $\mathrm{Au}_{2} \mathrm{P}_{3}$ phase, consistently with bulk thermodynamic data $[9,10]$. However, evolved gas analysis indicated that the evolution of phosphorus during vacuum annealing of $\mathrm{Au}$ and $\mathrm{Au}$ based metallizations is significant [11, 12].

In this work we report first quantitative measurements of the amount of phosphorus evaporated during annealing of $\mathrm{Au} / \mathrm{InP}$ contacts and we compare the 
loss of $P$ when contact is heated in either "open" or dielectric capped "closed" system. The method consists in capturing the evaporated $P$ species within a thin-film collector and their subsequent counting using Rutherford backscattering (RBS) technique [13]. These collectors consist of $100 \mathrm{~nm}$ Cr film deposited by DC magnetron sputtering onto oxidized Si substrates. They were placed during thermal processing, face-to-face, on top of metallized InP surfaces. After annealings the composition of $\mathrm{Si} / \mathrm{SiO}_{2} / \mathrm{Cr}$ collectors was analyzed by $2 \mathrm{MeV}{ }^{4} \mathrm{He}^{+} \mathrm{RBS}$ technique. The energy of $2 \mathrm{MeV}$ is sufficient to fully resolve $\mathrm{P}$ signal from the $\mathrm{Cr}$ signal in RBS spectra and to determine the amount of phosphorus in the Cr matrix from the ratio of integrated yield in the $\mathrm{P}$ peak to the integrated yield in the Cr peak. Complementary analysis involved RBS measurements of composition profiles of $\mathrm{Au} / \mathrm{InP}$ contacts.

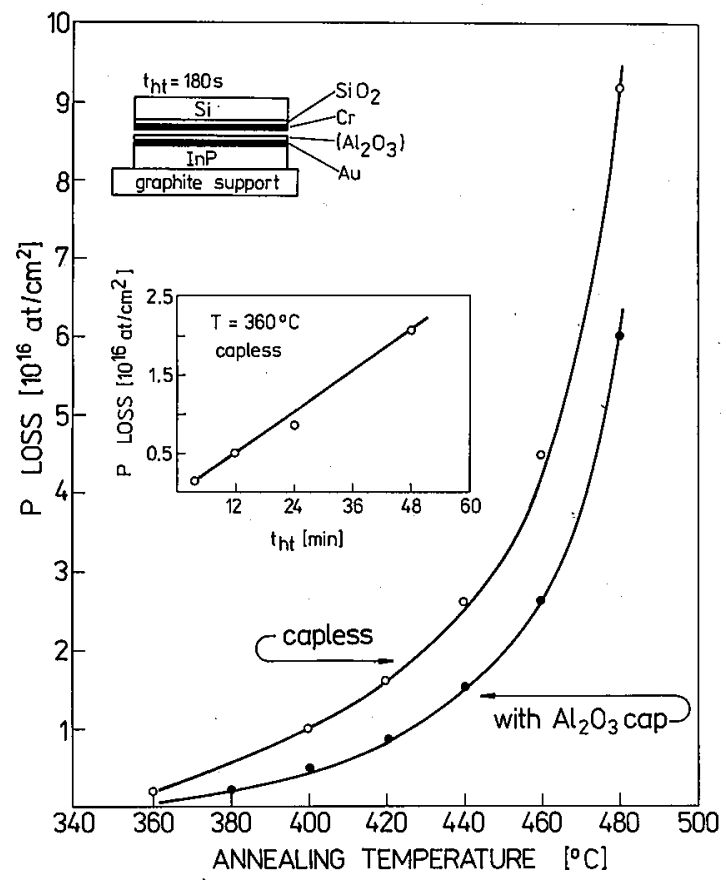

Fig. 1. The dependence of phosphorus losses from $A u(200 \mathrm{~nm}) / \mathrm{InP}$ contacts annealed either with or without capping layer on the temperature of heat treatment. The insert shows the time dependence of the amount of $\mathrm{P}$ evaporating from uncapped contact during annealing at $360^{\circ} \mathrm{C}$.

(100) oriented InP wafers $S n$ doped to $n=1 \times 10^{17} \mathrm{~cm}^{-3}$ were used in the present experiments. $200 \mathrm{~nm}$ thick $\mathrm{Au}$ films were deposited on chemically etched (in $\mathrm{HCl}-\mathrm{CH}_{3} \mathrm{COOH}-\mathrm{H}_{2} \mathrm{O}_{2}$ solution) surfaces by thermal evaporation in oil-free vacuum at pressure $5 \times 10^{-7} \mathrm{Tr}$. $200 \mathrm{~nm}$ thick $\mathrm{Al}_{2} \mathrm{O}_{3}$ layers prepared by $\mathrm{RF}$ magnetron sputtering were used for cap annealings. Heat treatments were carried out by means of furnace annealing under flowing $\mathrm{H}_{2}$. To get better insight into 
the mechanism of contact reaction we dealt in greater detail with low-temperature effects.
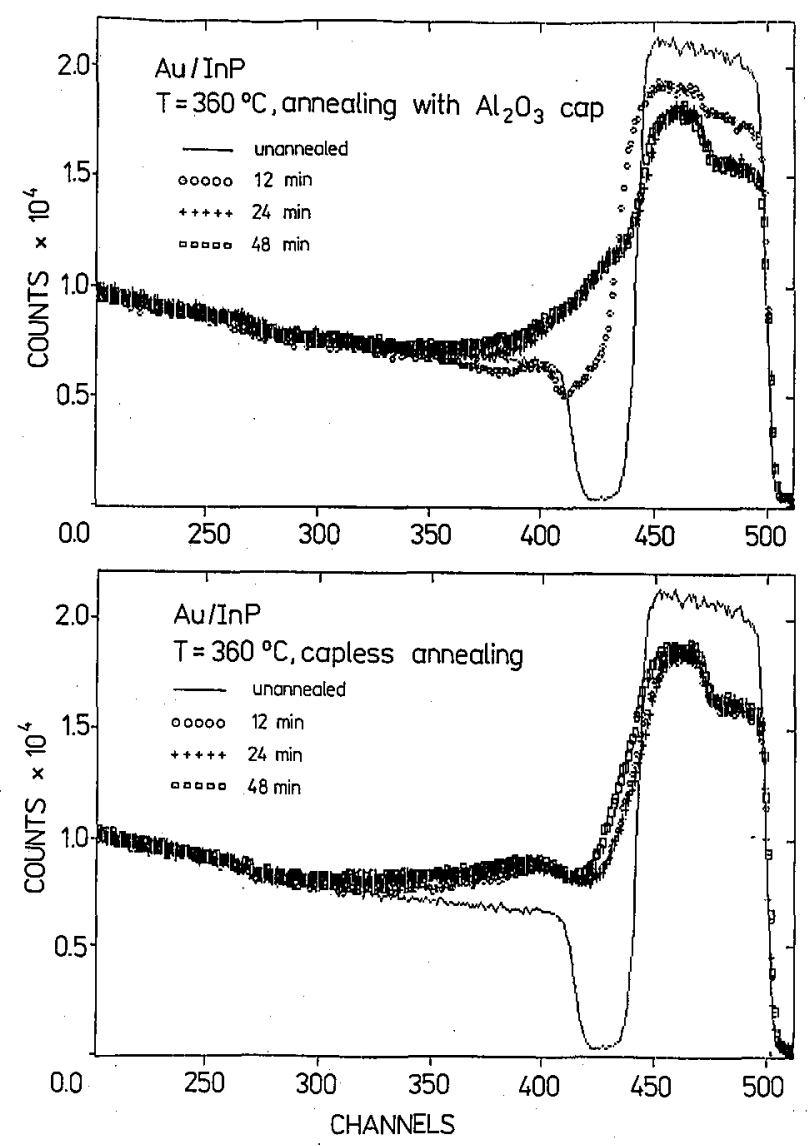

Fig. 2. $2 \mathrm{MeV}$ RBS spectra of $\mathrm{Au}(200 \mathrm{~nm}) / \mathrm{InP}$ contacts annealed at $360^{\circ} \mathrm{C}$ either without (a) or under capping layer (b).

In Fig. 1 the amounts of $\mathrm{P}$ losses from $\mathrm{Au} / \mathrm{InP}$ contacts heat treated at temperature in the range $360-480^{\circ} \mathrm{C}$ are given. The data indicate that in open system phosphorus vaporization occurs at any stage of contact reaction. Phosphorus release changes from $1.8 \times 10^{15}$ at. $/ \mathrm{cm}^{2}$ to $9.2 \times 10^{16}$ at. $/ \mathrm{cm}^{2}$ for the annealings of 3 minutes duration and increases for longer times. At $360^{\circ} \mathrm{C}$ the amount of $\mathrm{P}$ evaporating during annealing for $48 \mathrm{~min}$ increases to $2.07 \times 10^{16}$ at. $/ \mathrm{cm}^{2}$, the quantity detected after 3 min anneal at about $430^{\circ} \mathrm{C}$. The effect of capping layer in suppressing the loss of phosphorus from $\mathrm{Au} / \mathrm{InP}$ contact is quantitatively similar to that observed in gold based contacts to GaAs [14]. However, comparing with $\mathrm{Au} / \mathrm{GaAs}$ system, where the application of capping layer was shown to effectively suppress the decomposition of underlying semiconductor, here, the use of an encapsulant seems to change the repartition of intermetallic phases in contact 
reaction rather than the extent of $\mathrm{Au} / \mathrm{InP}$ contact reaction.

In Fig. 2 RBS spectra of $\mathrm{Au} / \mathrm{InP}$ contacts annealed at $360^{\circ} \mathrm{C}$ either with or without capping layer are compared. It should be mentioned that all these contacts contain $\mathrm{Au}_{3} \mathrm{In}$ alloy as indicated by the change of their color from gold to pink. Two characteristic features should be pointed out. First, a decrease in height of $\mathrm{Au}$ spectrum progresses with higher rate in contacts annealed without capping layer. Second, the pronounced low-energy step in the spectrum of metallization annealed without capping layer occurs at the depth corresponding to the original interface. These suggest that the complete transition from diluted $\alpha-\mathrm{Au}(\mathrm{In})$ alloy to $\mathrm{Au}_{3} \mathrm{In}$ phase is slowed down by sealing the contact with capping layer.

The above results indicate that the kinetics of $\mathrm{Au} / \mathrm{InP}$ reaction is strongly pressure dependent, conformable to other $\mathrm{Au} / \mathrm{III}-\mathrm{V}$ semiconductor systems. The data should be helpful to evaluate the outcome of contact reaction.

\section{References}

[1] A. Hiraki, K. Shuto, S. Kim, W. Kammura, M. Iwami, Appl. Phys: Lett. 31, 611 (1977).

[2] P.W. Chye, I. Lindau, P. Pianetta, C.M. Garner, S.Y.Su, W.E. Spicer, Phys. Rev. B 18, 6654 (1978).

[3] N.S. Fatemi, V.G. Weizer, J. Appl. Phys. 67, 1934 (1990).

[4] A. Piotrowska, P. Auvray, A. Guivarc'h, G. Pelous, P. Henoc, J. Appl. Phys. 52, 5112 (1981).

[5] A. Piotrowska, P. Auvray, B. Guenais, A. Guivarc'h, G. Pelous, P. Henoc, Electron Technol. 15, 13 (1982).

[6] O. Wada, J. Appl. Phys. 57, 1901 (1985).

[7] V.G. Weizer, N.S. Fatemi, J. Appl. Phys. 68, 2275 (1990).

[8] A. Barna, B. Pecz, J. Electron Microsc. Techn. 18, 325 (1991).

[9] I. Mojzes, D. Szigethy, R. Veresegyhazy, Electron. Lett. 19, 117 (1983).

[10] M. Murakami, Y.C. Shih, H.J. Kim, W.H. Price, Proc. 2oth Int. Conf. Solid State Dev. Mat. D-a-3, 283 (1988).

[11] M. Hansen, Constitution of Binary Alloys, McGraw-Hill, New York 1958.

[12] A. Piotrowska, E. Kamińska, M. Guziewicz, R. Veresegyhazy, I. Mojzes, B. Pecz, Acta Phys. Pol. A 80, 457 (1991).

[13] T.E. Haynes, W.K. Chu, T.L. Aselage, S.T. Picraux, Appl. Phys. Lett. 49, 666 (1986).

[14] A. Piotrowska, E. Kaminiska, S. Kwiatkowski, A. Turos, to be published. 